\title{
Tendon degeneration and chronic shoulder pain: changes in the collagen composition of the human rotator cuff tendons in rotator cuff tendinitis
}

\author{
G P Riley, R L Harrall, C R Constant, M D Chard, T E Cawston, B L Hazleman
}

\begin{abstract}
Objectives-To analyse the collagen composition of normal adult human supraspinatus tendon and to compare with: (1) a flexor tendon (the common biceps tendon) which is rarely involved in any degenerative pathology; (2) degenerate tendons from patients with chronic rotator cuff tendinitis.

Methods-Total collagen content, collagen solubility and collagen type were investigated by hydroxyproline analysis, acetic acid and pepsin digestion, cyanogen bromide peptide analysis, SDS-PAGE and Western blotting.

Results-The collagen content of the normal cadaver supraspinatus tendons (n=60) was $96.3 \mu \mathrm{H}$ HYPRO/mg dry weight (range 79.3-113.3) and there was no significant change across the age range 11 to 95 years. There was no significant difference from the common biceps tendon [93.3 (13.5) $\mu$ g HYPRO/mg dry weight, $n=24]$. Although extremely insoluble in both acetic acid and pepsin, much of the collagen was soluble after cyanogen bromide digestion [mean $47.9 \%$ $(29.8)]$. Seventeen per cent $(10 / 60)$ of the 'normal' cadaver supraspinatus tendon sample contained more than $5 \%$ type III collagen, although none of the common biceps tendons had significant amounts. Degenerate supraspinatus and subscapularis tendons had a reduced collagen content $[83.8(13.9) \mu \mathrm{g} / \mathrm{mg}$ dry weight and $76.9(16 \cdot 8) \mu \mathrm{g} / \mathrm{mg}$ dry wt respectively) and were more soluble in acetic acid, pepsin and cyanogen bromide $(p<0.001)$. Eighty two per cent $(14 / 17)$ of supraspinatus tendons and $100 \%(8 / 8)$ of subscapularis tendons from patients with tendinitis contained more than $5 \%$ type III collagen. Conclusions-The changes in collagen composition in rotator cuff tendinitis are consistent with new matrix synthesis, tissue remodelling and wound healing, in an attempt to repair the tendon defect, even in old and degenerate tendons. An increase in type III collagen in some 'normal' cadaver supraspinatus tendons is evidence that changes in collagen synthesis and turnover may precede
\end{abstract}

tendon rupture. These changes may be the result of repeated minor injury and microscopic fibre damage or a consequence of local factors such as reduced vascular perfusion, tissue hypoxia, altered mechanical forces and the influence of cytokines. These collagenous changes may accumulate with age and substantially weaken the tendon structure, predisposing the tendon to rotator cuff tendinitis and eventual tendon rupture.

(Ann Rheum Dis 1994; 53: 359-366)

Rotator cuff 'tendinitis' is a debilitating degenerative condition and one of the principal causes of chronic shoulder pain. ${ }^{12}$ Although often considered to resolve with time, the prognosis is poor in a significant number of patients. $^{3-5}$ Conventional conservative therapies, including rest, physiotherapy and nonsteroidal anti-inflammatory therapy, are often of limited benefit and many patients do not respond to local corticosteroid injections. ${ }^{67}$

Rotator cuff tendinitis is not often treated surgically and because diagnosis does not require biopsy of the tendons, our understanding of the pathology is relatively poor. Most patients present in middle age and it is generally believed that age-related degenerative changes in the tendon are important. ${ }^{8}$ The supraspinatus tendon is most commonly affected, usually at the 'critical zone', one centimetre from the bone insertion. ${ }^{9}$ Impingement against the acromium and overlying structures has been advocated as the principal cause of rotator cuff tears. ${ }^{10}$ Other studies, however, have shown that this may be a secondary feature of degeneration. ${ }^{11}$ The 'critical zone' is a region of blood vessel anastomoses $^{12}$ and a reduction in blood perfusion as a result of age or injury can cause degeneration of tendons. ${ }^{13}$ In addition, repetitive, overhead activities related to certain sports and occupations have been associated with shoulder pain and tendinitis. ${ }^{14}$

Previous studies of rotator cuff degeneration and rupture have been histopathological and biochemical studies of immature and animal flexor tendons and may not be relevant to ageing human rotator cuff tendons. Collagen is 
the principal matrix component and the major structural protein of all connective tissues. At least 14 types of collagen have been identified and this molecular heterogeneity has important consequences for the structure and function of the matrix. ${ }^{15} 16$ Changes in the relative proportions of the collagen types have been described in both normal and pathological conditions. ${ }^{17-20}$ Normal tendon is composed almost entirely of type I collagen. ${ }^{21}$ An increased proportion of type III collagen is produced in the early phase of tendon wound healing. ${ }^{22}$ This is gradually replaced by type I collagen as the scar tissue matures and the mechanical strength of the wound returns to normal, although an abnormal collagen composition may persist many months after injury. ${ }^{22}$ Type III collagen tends to form collagen fibrils of small average diameter. ${ }^{23}$ Consequently the maintenance and regeneration of the normal collagen matrix are essential for the structure and function of the tendon. This study was conducted to characterise the changes in collagen composition in a large sample of human supraspinatus tendons without any medical history of rotator cuff disease and to compare these changes with a sample of tendon biopsy specimens taken from patients with advanced rotator cuff tendinitis.

\section{Materials and methods}

TISSUE PREPARATION AND PROCESSING

Tendon specimens were dissected free of muscle, fat and all remains of the subacromial bursa and surrounding connective tissues. The specimen was freeze dried and powdered in a Spex freezer mill and stored desiccated at $-20^{\circ} \mathrm{C}$.

MEASUREMENT OF TENDON WATER CONTENT Wet specimens of tendon were weighed, then frozen and freeze dried until no further weight change was recorded (at least 24 hours). The water content of the tendons was calculated by dividing the difference in wet and dry weights by the original wet weight and expressed as a percentage.

\section{COLLAGEN ANALYSIS}

Powdered tendons (10-15 mg dry weight) were digested in $1.0 \mathrm{ml}$ of $0.1 \mathrm{M}$ phosphate buffer $\mathrm{pH} 7 \cdot 0$ containing $125 \mu \mathrm{g} / \mathrm{ml}$ of papain ( $2 \times$ crystallised, Sigma), $10 \mathrm{mM}$ cysteine $\mathrm{HCl}$ and $2 \mathrm{mM}$ EDTA, for 18 hours at $65^{\circ} \mathrm{C}$. Some tissue digests required an additional period of digestion with fresh papain $(100 \mu l$ of $10 \times$ concentrated papain solution) for four to six hours. An aliquot of the digest was hydrolysed and assayed for hydroxyproline using a microtitre plate modification of the method of Bergman and Loxley. ${ }^{24} \mathrm{~A}$ stock reagent of $7 \%$ $(\mathrm{w} / \mathrm{v})$ chloramine $\mathrm{T}$ in water was diluted $1: 4$ in acetate-citrate buffer (57 g sodium acetate, $37.5 \mathrm{~g}$ tri-sodium citrate, $5.5 \mathrm{~g}$ citrate acid, 385 $\mathrm{ml}$ propan-2-ol in 1.01 water). A stock reagent of $20 \mathrm{~g} \mathrm{p}$-dimethylamino-benzaldehyde (DAB) dissolved in $30 \mathrm{ml}$ of $60 \%$ perchloric acid was diluted 1:3 in propan-2-ol. Specimens were hydrolysed in $6 \mathrm{M} \mathrm{HCl}$ for 20 hours at $105^{\circ} \mathrm{C}$ and the hydrolysate neutralised by drying over $\mathrm{NaOH}$ in vacuo. The residue was dissolved in water and duplicate aliquots $(40 \mu \mathrm{l})$ were added to the sample wells of a 96 well plate. Chloramine-T reagent $(25 \mu \mathrm{l})$ was added to each sample well and DAB reagent $(150 \mu \mathrm{l})$ was added after four minutes. The plate was covered and heated to $60^{\circ} \mathrm{C}$ for 40 minutes, cooled for five minutes to room temperature, then scanned at $560 \mathrm{~nm}$ using a Titertek Multiscan II plate reader. Hydroxyproline standards of $5-30 \mu \mathrm{g} / \mathrm{ml}$ were prepared in distilled water. An internal standard of $5 \mu \mathrm{g}$ HYPRO was included in some samples to check for quenching. The collagen content was calculated using a multiplication factor of 6.94 for type I collagen and 5.56 for type III collagen.

SOLUBLE COLLAGEN ANALYSIS

Powdered tendons (10-15 mg dry weight) were extracted with $1.0 \mathrm{ml}$ of $0.5 \mathrm{M}$ acetic acid for 48 hours at $4^{\circ} \mathrm{C}$ and the acetic acid soluble collagen was separated by centrifugation $\left(15000 \mathrm{~g}\right.$ for 10 minutes at $4^{\circ} \mathrm{C}$ ) and analysed for HYPRO. The insoluble residue was digested in $1.0 \mathrm{ml}$ of $0.5 \mathrm{M}$ acetic acid containing $1.0 \mathrm{mg} / \mathrm{ml}$ pepsin for 24 hours at $4^{\circ} \mathrm{C}$, then centrifuged ( $15000 \mathrm{~g}$ for 10 minutes at $4^{\circ} \mathrm{C}$ ) and the supernatant analysed for HYPRO. The pepsin insoluble residue was lyophilised and stored at $-20^{\circ} \mathrm{C}$. Soluble collagen extracts were taken up in SDS sample buffer, heated to $100^{\circ} \mathrm{C}$ for five minutes and subjected to $6 \%$ SDS-PAGE using the Bio-Rad Mini-Protean II system and Laemmli buffers. ${ }^{25}$ Interrupted SDS-PAGE and delayed reduction with $\beta$-mercaptoethanol was performed essentially as described by Sykes et al. ${ }^{26}$ Western blotting was conducted essentially as described by Towbin et al, ${ }^{27}$ using a semi-dry Novablot apparatus (Pharmacia-LKB) and a transfer buffer of $48 \mathrm{mM}$ Tris, $0.0375 \%$ SDS and 39 $\mathrm{mM}$ glycine (methanol was omitted). Goat polyclonal antibodies against human and bovine collagens, types I, II and III were obtained from Southern Biotechnology Associates, Birmingham, Alabama, USA. A second antibody prepared against goat immunoglobulins and linked to horse radish peroxidase was obtained from Dako Ltd, UK. Standard collagen types I, III, IV, V and VI were prepared from human placenta by standard techniques involving pepsin digestion and differential salt precipitation. ${ }^{28}$

\section{CYANOGEN BROMIDE PEPTIDE MAPPING}

The acetic acid and pepsin insoluble tendon residue was digested in a solution of $10 \mathrm{mg} / \mathrm{ml}$ cyanogen bromide in $70 \%$ formic acid, essentially as described previously. ${ }^{29} 30$ The reaction was conducted at room temperature in a nitrogen atmosphere for a period ranging from four to 24 hours. Some tendon specimens were extracted with $4 \mathrm{M}$ guanidine $\mathrm{HCl}$, both with and without the reducing agent DTT, 
before digestion. Soluble peptides were separated from the undigested residue by centrifugation (15000 g for 10 minutes) and an aliquot of the supernatant was diluted in 10 volumes of water and freeze dried. Collagen peptides were dissolved in $0 \cdot 1 \mathrm{M}$ acetic acid, an aliquot was taken for HYPRO analysis and the remainder was dissolved in SDS sample buffer for $12.5 \%$ SDS-PAGE. Gels were stained overnight with Coomassie Brilliant Blue G250, destained and scanned using an LKB Ultrascan XL scanning densitometer. The concentration of each collagen type was calculated by reference to representative peptides of human collagen standards in adjacent sample lanes. Because of the extreme variability in collagen solubility of different tendons, the type III content was expressed relative to the total collagen content of the tendon, calculated by HYPRO analysis of the papain digest.

STATISTICAL ANALYSIS

The difference between sample group means was tested for statistical significance by the

Table 1 Specimens of adult human tendon collected

\begin{tabular}{llll}
\hline Tendon specimens & Observations & $\begin{array}{l}\text { Number of } \\
\text { specimens }\end{array}$ & $\begin{array}{l}\text { Mean age in years } \\
\text { (range) }\end{array}$ \\
\hline Supraspinatus (cadaver) & macroscopically 'normal' & 60 & $57 \cdot 7(11-95)$ \\
& 'ruptured' tendons & 11 & $81 \cdot 2(60-94)$ \\
& 'thin/degenerate' tendons & 4 & $78 \cdot 7(67-86)$ \\
& 'calcified' tendons & 5 & $82 \cdot 0(76-94)$ \\
Common biceps (cadaver) & misc abnormalities & 3 & $57 \cdot 3(43-84)$ \\
Supraspinatus biopsy & macroscopically 'normal' & 24 & $53 \cdot 6(12-83)$ \\
& 'tendinitis' (cuff tear) & 26 & $59 \cdot 5(38-80)$ \\
Subscapularis biopsy & 'calcifying tendinitis' & 5 & $52 \cdot 2(47-63)$ \\
& fracture repair & 2 & $51 \cdot 5(25$ and 78$)$ \\
& 'tendinitis' (cuff tear) & 8 & $73 \cdot 4(68-80)$ \\
& stabilisation operation & 5 & $25 \cdot 2(19-31)$ \\
& prosthetic replacement & 7 & $57 \cdot 3(40-76)$ \\
& fracture repair & 1 & $25(25)$ \\
\hline
\end{tabular}

Table 2 Water content of rotator cuff tendons

\begin{tabular}{llll} 
Tendon specimens & Observation & $\begin{array}{l}\text { Mean age } \\
\text { (range) }\end{array}$ & $\begin{array}{l}\text { Water content \% } \\
\text { mean (SD) }\end{array}$ \\
\hline Cadaver supraspinatus & macroscopically 'normal' & $67 \cdot 6(19-96)$ & $75 \cdot 1 \%(3 \cdot 9)$ \\
Supraspinatus biopsy & 'tendinitis' (rotator cuff tear) & $58 \cdot 7(38-81)$ & $84 \cdot 9 \%(4 \cdot 8)^{\star \star \star}$ \\
Subscapularis biopsy & 'tendinitis' (rotator cuff tear) & $72 \cdot 8(65-80)$ & $84 \cdot 8 \%(3 \cdot 4)^{\star \star \star}$ \\
\hline
\end{tabular}

$\star \star \star \mathrm{p}<0.001$, calculated by Mann Whitney test.

Table 3 Collagen content of human tendons

\begin{tabular}{|c|c|c|}
\hline Tendon specimens & $\begin{array}{l}\text { HYPRO content } \\
\mu g / m g \text { dry wt, mean (SD) }\end{array}$ & $\begin{array}{l}\text { Collagen (type I) content } \\
\% \text { dry wt, mean (SD) }\end{array}$ \\
\hline \multicolumn{3}{|l|}{ Supraspinatus (cadaver) } \\
\hline macroscopically 'normal' & $96 \cdot 3(7 \cdot 9)$ & $66 \cdot 6(5 \cdot 3)$ \\
\hline 'ruptured' tendons & $83 \cdot 5(11 \cdot 2)^{\star \star}$ & $57 \cdot 9(7 \cdot 8)^{\star \star}$ \\
\hline 'thin/degenerate' tendons & $83 \cdot 8(12 \cdot 5)^{\star \star}$ & $58 \cdot 2(8 \cdot 7)^{\star \star}$ \\
\hline 'calcified' tendons & $74.9(7 \cdot 2)^{\star \star \star}$ & $52 \cdot 0(5 \cdot 0)^{\star \star \star}$ \\
\hline misc abnormalities & $90 \cdot 9(14 \cdot 8)$ & $63 \cdot 1(10 \cdot 3)$ \\
\hline \multicolumn{3}{|l|}{ Common biceps (cadaver) } \\
\hline macroscopically 'normal' & $93.3(13.5)$ & $64 \cdot 8(9 \cdot 2)$ \\
\hline \multicolumn{3}{|l|}{ Supraspinatus biopsy } \\
\hline 'tendinitis' (cuff tear) & $83.8(13.9)^{\star \star \star}$ & $58 \cdot 3(9 \cdot 7)^{\star \star \star}$ \\
\hline 'calcifying tendinitis' & $68.5(17.9)^{\star \star \star}$ & $47 \cdot 6(12 \cdot 4)^{\star \star \star}$ \\
\hline fracture repair & $81 \cdot 2(5 \cdot 1)$ & $56 \cdot 4(3 \cdot 5)$ \\
\hline \multicolumn{3}{|l|}{ Subscapularis biopsy } \\
\hline 'tendinitis' (cuff tear) & $76 \cdot 9(16 \cdot 8)^{\star \star \star}$ & $53 \cdot 4(11 \cdot 7)^{\star \star \star}$ \\
\hline stabilisation operation & $97 \cdot 0(12 \cdot 8)$ & $67 \cdot 4(8.9)$ \\
\hline prosthetic replacement & $78 \cdot 3(17 \cdot 0)^{\star \star}$ & $54 \cdot 4(11 \cdot 8)^{\star \star}$ \\
\hline fracture repair & $54 \cdot 3$ & $37 \cdot 7$ \\
\hline
\end{tabular}

${ }^{\star \star} \mathrm{p}<0.01,{ }^{\star \star \star} \mathrm{p}<0.001$, calculated by Mann Whitney test. non-parametric analogue of the two-sample $t$ test, the Mann-Whitney test. Sample means were considered significantly different if $\mathrm{p}<0.05$.

TENDON SPECIMENS

Specimens of supraspinatus tendons and common biceps tendons were collected from cadavers at necropsy. None of the subjects had any known history of tendinitis or shoulder pathology. Shoulders with gross rotator cuff lesions were excluded from the study. Surgical biopsies of rotator cuff tendons (supraspinatus and subscapularis tendon) were collected by CRC, at Addenbrookes Hospital, Cambridge, UK. Patients with chronic 'tendinitis' (a rotator cuff tear) had been treated conservatively with at least one corticosteroid injection before surgery. Tendons with 'calcifying tendinitis' had radiographically detectable mineral deposits-tissue was excised from around the deposit. Biopsies of tendons were also taken during fracture repairs, prosthetic shoulder replacement, and 'stabilisation' operations to prevent recurrent dislocation. The biopsy specimens varied in size from $100 \mathrm{mg}$ up to three grams wet weight.

\section{Results}

The tendon specimens are listed in table 1. Eighty two supraspinatus tendons (forty eight males) were obtained from cadaver shoulders, 42 specimens from the right hand side. Bilateral specimens were obtained from three cadavers (55, 59 and 91 years). Although none of the cadavers had any known history of shoulder disorders, 22 specimens had some form of macroscopic abnormality, according to the subjective assessment of one of us (MDC). Eleven specimens (five males) had some tendon fibre disruption, fraying or partial thickness tears and were designated 'ruptured'; five specimens (two males) had a thin, atrophic appearance and were designated 'thin/degenerate'; five specimens (two males) contained white mineral deposits and were designated 'calcified'; three specimens were of an otherwise abnormal appearance and designated 'miscellaneous abnormalities'. One specimen was both 'ruptured' and 'calcified' and is represented twice in the table. Eight 'normal' cadaver specimens (three males) between the ages of 19 and 88 were divided into approximately equal bone and muscle ends in a study of regional variation within the tendon. All of the common biceps tendons were macroscopically normal.

WATER CONTENT

Supraspinatus and subscapularis tendons with chronic 'tendinitis' had a significantly greater water content compared with macroscopically 'normal' supraspinatus tendons (table 2). There was no significant difference in water content between the bone and muscle ends of the tendon (data not shown). 


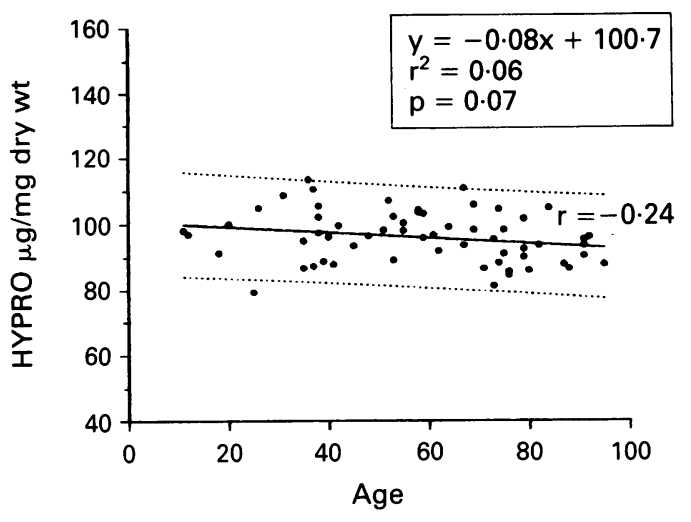

Figure 1 The collagen content of adult supraspinatus tendon with age. Macroscopically 'normal' cadaver supraspinatus tendons (age range $11-95, n=59$ ) were papain digested for 24 hours at $65^{\circ} \mathrm{C}$ and duplicate aliquots were hydrolysed ( $6 \mathrm{M} \mathrm{HCl} \mathrm{for} 20$ hours at $105^{\circ} \mathrm{C}$ ) and analysed for HYPRO. Data represent the mean of three papain digests, expressed relative to the tendon dry weight. Dotted lines represent $95 \%$ confidence limits calculated by linear regression.

\section{TOTAL COLLAGEN CONTENT}

The hydroxyproline content of the tendon specimens is shown in table 3 . The majority (57/59) of the 'normal' cadaver tendon specimens were within two standard deviations of the sample mean and the normal range was accepted to be within $80-110 \mu \mathrm{g}$ HYPRO/mg dry wt, mean (2 SD). Assuming that the contribution of hydroxyproline from noncollagenous proteins such as elastin was negligible, the calculated collagen type I content was estimated to be $66 \cdot 6 \%(5 \cdot 3)$ of the tendon dry weight (range $55 \cdot 1 \%-78 \cdot 7 \%$ ). See table 3.

There was no significant difference in collagen concentration between males and females, left and right shoulders or muscle and bone ends of the tendon (data not shown). In addition, there was no significant difference between the supraspinatus and common biceps tendons and there was no change with increasing specimen age $(p=0.07$ and $p=0.28$ respectively). See fig 1 .

Cadaver supraspinatus tendons which had visible evidence of previous episodes of tendon pathology and/or degeneration, including specimens designated 'ruptured', 'thin/degenerate' and 'calcified', had a significantly

Table 4 Collagen solubility

\begin{tabular}{lll}
\hline Tendon specimens & \multicolumn{2}{l}{ Soluble collagen as a percentage of dry wt, mean $(S D)$} \\
\cline { 2 - 3 } & \multicolumn{1}{l}{ Acetic acid soluble } & Pepsin soluble \\
\hline Supraspinatus (cadaver) & & \\
macroscopically 'normal' & $0 \cdot 6(0 \cdot 3)$ & $1 \cdot 0(0 \cdot 4)$ \\
'ruptured' tendons & $0 \cdot 4(0 \cdot 3)$ & $1 \cdot 5(0 \cdot 7)$ \\
'thin/degenerate' tendons & $1 \cdot 0(0 \cdot 9)$ & $6 \cdot 0(7 \cdot 9)$ \\
'calcified' tendons & $0 \cdot 4(0 \cdot 3)$ & $1 \cdot 8(0 \cdot 8)$ \\
misc abnormalities & $0 \cdot 9(0 \cdot 5)$ & $1 \cdot 3(0 \cdot 5)$ \\
Common biceps (cadaver) & $0 \cdot 5(0 \cdot 4)$ & $2 \cdot 3(4 \cdot 9)$ \\
macroscopically 'normal' & $1 \cdot 9(0 \cdot 9)^{\star \star \star}$ & $9 \cdot 1(4 \cdot 0)^{\star \star \star}$ \\
Supraspinatus biopsy & $2 \cdot 5(2 \cdot 2)^{\star \star \star}$ & $3 \cdot 7(0 \cdot 8)^{\star \star \star}$ \\
'tendinitis' (cuff tear) & $2 \cdot 2(0 \cdot 5)^{\star \star \star}$ & $7 \cdot 8(4 \cdot 1)^{\star \star \star}$ \\
'calcifying tendinitis' & $1 \cdot 2(0 \cdot 7)^{\star \star \star}$ & $14 \cdot 9(13 \cdot 1)^{\star \star \star}$ \\
fracture repair & $2 \cdot 6(1 \cdot 5)^{\star \star \star}$ & $4 \cdot 3(1 \cdot 4)^{\star \star \star}$ \\
Subscapularis biopsy & $2 \cdot 4(3 \cdot 1)^{\star \star \star}$ & $8 \cdot 0(8 \cdot 6)^{\star \star \star}$ \\
'tendinitis' (cuff tear) & $0 \cdot 9(-)$ & $11 \cdot 2(-)$ \\
stabilisation operation & prosthetic replacement &
\end{tabular}

$\star \star \star \mathrm{p}<0.001$, calculated by Mann Whitney test. reduced collagen concentration $(p<0.01$, $\mathrm{p}<0.01$ and $\mathrm{p}<0.001$ respectively). See table 3. A similar trend was observed in biopsy specimens from patients with active disease, including supraspinatus and subscapularis specimens from patients with chronic tendinitis $(p<0.001$ each $)$, supraspinatus tendons with calcifying tendinitis $(p<0.001)$ and subscapularis tendons from joint replacement operations $(\mathrm{p}<0 \cdot 01)$.

\section{SOLUBLE COLLAGEN ANALYSIS}

The proportion of acid and pepsin soluble collagen was very low in all the 'normal' cadaver tendon specimens and comprised in total less than $3 \%$ of the tendon dry weight (table 4). There was no significant difference between any of the cadaver tendons, regardless of the macroscopic appearance and age of the tendon.

The biopsy specimens of supraspinatus and subscapularis tendons were significantly more soluble in both acetic acid and pepsin than the cadaver specimens $(p<0.001)$. However, the pepsin soluble collagen comprised on average less than $15 \%$ of the dry weight of the subscapularis tendons and less than $10 \%$ of the dry weight of the supraspinatus tendons.

Acetic-acid soluble collagen was taken up in SDS sample buffer and run on $6 \%$ reducing SDS-PAGE. No collagen bands were detected from any of the specimens after staining with $0 \cdot 25 \%$ Coomassie Blue G250 or after Western blot analysis with specific anti-type I and antitype III collagen antibodies (data not shown). This suggests that either the collagen concentration was beneath the limits of detection, or the extracted hydroxyproline was in peptide form, perhaps as a consequence of proteolytic cleavage.

The pepsin soluble collagen was separated by SDS PAGE with interrupted electrophoresis and reduction. The method exploits the presence of inter-chain disulphide bonds in type III collagen and allows the separation of type I and type III collagen. Pepsin extracts from normal cadaver specimens all contained predominantly type I collagen, although a small amount of type III collagen was just visible in some specimens (fig 2).

Biopsy specimens from patients with chronic supraspinatus tendinitis also contained predominantly type I collagen, although there was a significant proportion of type III collagen, confirmed by Western blot analysis (fig 2). Quantitative analysis of the different collagens was not attempted, because the extracts represented only a small proportion of the total collagen. No other collagen types were unequivocally identified, although a minor band migrating above the $\alpha_{1}(I)$ chain was unaffected by reduction with $\beta$-mercaptoethanol and was possibly one of the type $V$ collagen $\alpha$ chains. A number of bands of lower molecular weight than the intact collagen $\alpha$ chains were probably proteolytic degradation products of type III collagen, although the degradation might have occurred during or after the collagen extraction. 

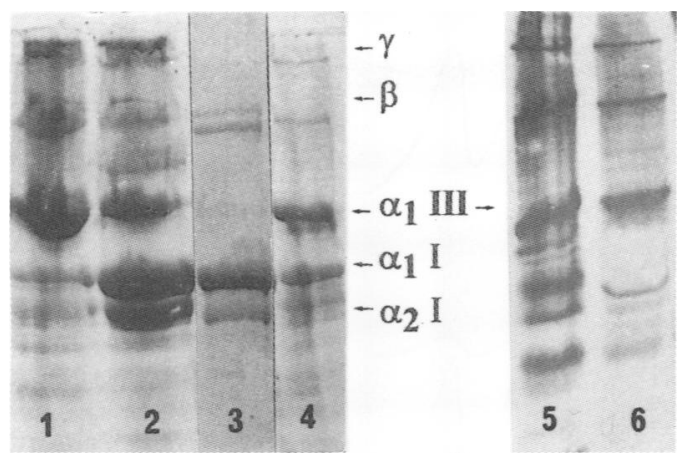

Figure 2 Interrupted SDS PAGE and Western blot analysis of soluble collagen. Pepsin soluble collagen was dissolved in SDS sample buffer and 6\% SDS PAGE was conducted for 10 minutes, then $1.0 \mathrm{mM} \beta$-mercaptoethanol was added to each sample lane and electrophoresis was continued to completion. Collagen was stained in $0.25 \%$ Coomassie Brilliant Blue G250 (lanes 1 to 4) or transferred to nitrocellulose and blotted with a specific goat polyclonal antisera prepared against bovine and human type III collagen (lanes 4 and 5).

Lanes 1, 6, type III collagen. Lane 2, type I collagen. Lane 3, 25 year old cadaver supraspinatus tendon. Lanes 4, 5, 70 year old supraspinatus tendon from patient with 'tendinitis'.

CYANOGEN BROMIDE SOLUBLE COLLAGEN Many of the elderly cadaver specimens were extremely resistant to cyanogen bromide digestion, even after acetic acid extraction and pepsin digestion. One possible explanation for the low solubility was an increase in the oxidation of methionine residues, preventing cleavage of the polypeptide chain. Prior reduction of the specimen, however, did not significantly increase the collagen solubility. Collagen yields were also not significantly higher after extraction with organic solvents to remove lipids; after extraction with chaotropic agents such as $4 \mathrm{M}$ guanidine $\mathrm{HCl}$ (both with and without dithiothreitol) to remove proteoglycans or after repeated extractions in cyanogen bromide ( $3 \times 24$ hours). Consequently, a standardised protocol was adopted and all of the tendon specimens were digested for 24 hours at room temperature.

There was a significant trend of decreasing cyanogen bromide solubility with increasing specimen age $(r=-0.35, p=0 \cdot 006)$. See fig 3 . There were some older specimens that were almost completely soluble and younger specimens with low solubility. The recovery of collagen was often extremely low, at least in

Table 5 Cyanogen bromide solubility and Type III collagen content

\begin{tabular}{|c|c|c|c|}
\hline Tendon specimens & $\begin{array}{l}\text { Collagen solubility } \\
\% \text { total collagen, } \\
\text { mean (SD) }\end{array}$ & $\begin{array}{l}\text { Type III collagen } \\
\% \text { total, mean (SD) }\end{array}$ & $\begin{array}{l}\text { No. specimens } \\
>5 \% \text { Type III }\end{array}$ \\
\hline \multicolumn{4}{|l|}{ Supraspinatus (cadaver) } \\
\hline macroscopically 'normal' & $47.9(29 \cdot 8)$ & $2 \cdot 75(3 \cdot 2)$ & $10 / 60$ \\
\hline 'ruptured' tendons & $23 \cdot 4(14 \cdot 8)^{\star \star}$ & $2 \cdot 3(2 \cdot 6)$ & $2 / 11$ \\
\hline 'thin/degenerate' tendons & $28 \cdot 3(24 \cdot 3)^{\star \star}$ & $5 \cdot 4(4 \cdot 7)$ & $2 / 4$ \\
\hline 'calcified' tendons & $33.3(30 \cdot 3)^{\star \star}$ & $3 \cdot 8(4 \cdot 6)$ & $2 / 4$ \\
\hline misc abnormalities & $26 \cdot 1(22 \cdot 7)^{\star \star}$ & $2 \cdot 6(2 \cdot 9)$ & $1 / 3$ \\
\hline \multicolumn{4}{|l|}{ Common biceps (cadaver) } \\
\hline macroscopically 'normal' & $27 \cdot 4(22 \cdot 0)^{\star \star}$ & $0 \cdot 0$ & $0 / 22$ \\
\hline \multicolumn{4}{|l|}{ Supraspinatus biopsy } \\
\hline 'tendinitis' (cuff tear) & $80 \cdot 0(17 \cdot 7)^{\star \star \star}$ & $9 \cdot 7(5 \cdot 7)^{\star \star \star}$ & $14 / 17$ \\
\hline 'calcifying tendinitis' & $75 \cdot 2(17 \cdot 9)^{\star \star \star}$ & $2 \cdot 2(1 \cdot 9)$ & $0 / 3$ \\
\hline fracture repair & $97 \cdot 4(3 \cdot 7)^{\star \star \star}$ & $3 \cdot 7(5 \cdot 2)$ & $1 / 2$ \\
\hline \multicolumn{4}{|l|}{ Subscapularis biopsy } \\
\hline 'tendinitis' (cuff tear) & $69 \cdot 1(21 \cdot 2)^{\star \star \star}$ & $9 \cdot 5(5 \cdot 6)^{\star \star \star}$ & $8 / 8$ \\
\hline stabilisation operation & $93.8(11.0)^{\star \star \star}$ & $6 \cdot 9(6 \cdot 5)$ & $2 / 5$ \\
\hline prosthetic replacement & $56 \cdot 0(23 \cdot 7)$ & $8 \cdot 4(3 \cdot 8)^{\star \star \star}$ & $6 / 7$ \\
\hline fracture repair & $42 \cdot 7(-)$ & $7 \cdot 4(-)$ & $1 / 1$ \\
\hline
\end{tabular}

${ }^{\star \star} \mathrm{p}<0.01,{ }^{\star \star \star} \mathrm{p}<0.001$, calculated by Mann Whitney test.

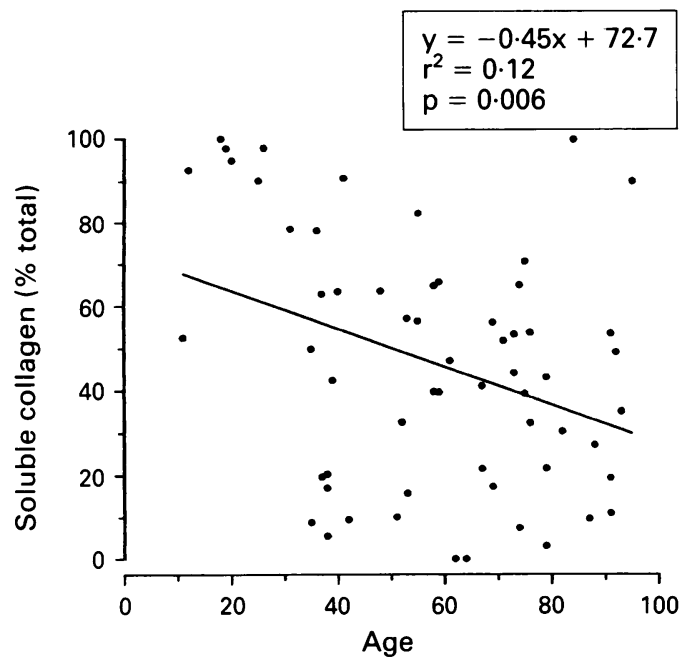

Figure 3 Cyanogen bromide solubility of the supraspinatus tendon. The acetic acid and pepsin insoluble residues of normal cadaver supraspinatus tendon specimens (age range 11-95 years, $n=60$ ) were digested in $10 \mathrm{mg} / \mathrm{ml}$ cyanogen bromide in $70 \%$ formic acid for 24 hours at $25^{\circ} \mathrm{C}$. The digest was centrifuged (15,000 g, 10 minutes) and an aliquot of the supernatant was diluted in 10 volumes of water and freeze dried. Soluble peptides were dissolved in $0.1 \mathrm{M}$ acetic acid and duplicate aliquots were hydrolysed $\left(6 \mathrm{M} \mathrm{HCl}\right.$ for 20 hours at $\left.105^{\circ} \mathrm{C}\right)$ and analysed for hydroxyproline. Data represent the mean of duplicate aliquots of a single cyanogen bromide digest, calculated as a proportion of the total collagen content, assuming a hydroxyproline concentration of $14 \cdot 4 \%$ dry weight (type I collagen).

part due to the presence of loose aggregates in suspension, even after centrifugation. This material could not be solubilised in $8 \mathrm{M}$ urea and was presumed to be due to the high degree of inter-molecular cross-linking between collagen molecules.

There was a significantly lower proportion of collagen extracted from macroscopically 'abnormal' cadaver supraspinatus tendons, although most were within the solubility range expected for the specimen age. The cadaver common biceps tendons were generally poorly soluble in cyanogen bromide, with only one specimen greater than $60 \%$ soluble. In contrast, a significantly greater proportion of the collagen was extracted from the biopsy specimens of rotator cuff tendons (table 5).

QUANTITATIVE CYANOGEN BROMIDE PEPTIDE ANALYSIS

The cyanogen bromide peptides were separated by $12 \cdot 5 \%$ SDS PAGE and identified by reference to previously published peptide maps. ${ }^{29}$ See fig 4 .

Peptides of type I and type III collagens were present in many specimens, but no peptides from other collagen types were identified. Dyebinding curves of standard collagens were obtained for the major cyanogen bromide peptides by densitometric analysis using a laser gel scanner. The $\alpha_{1}(\mathrm{I}) \mathrm{CB} 8$ peptide and the $\alpha_{1}$ (III)CB5 peptide were selected for quantitation of the collagen types I and III respectively (fig 4). These peptides were of approximately the same size (263 and 223 amino acids respectively), are not known to be involved in collagen cross-linking and exhibited a linear dye-binding response up to $125 \mu \mathrm{g}$ of collagen equivalent (data not shown). 


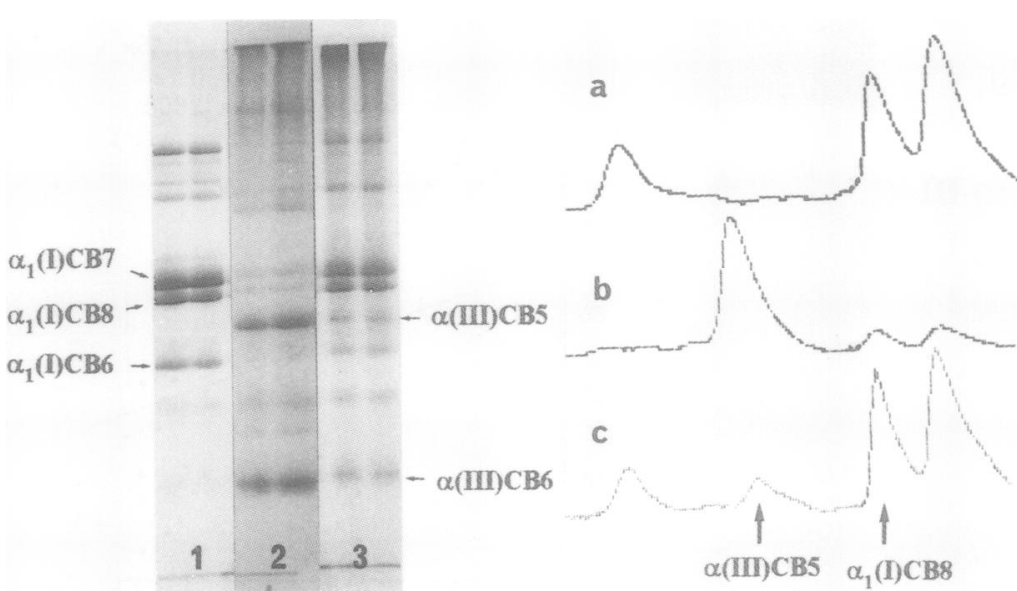

Figure $4 \quad 12 \cdot 5 \%$ SDS-PAGE of cyanogen bromide peptides. Cyanogen bromide peptides were diluted in SDS sample buffer, separated by non-reducing $12.5 \%$ SDS PAGE and stained overnight with $0 \cdot 25 \%$ Coomassie Brilliant Blue G250. The dye binding absorbance of representative peptides was measured with a scanning laser densitometer.

Lane 1, Type I collagen. Lane 2, Type III collagen. Lane 3, 80 year old subscapularis tendon from patient with tendinitis.

Scan traces: (A) Type I collagen (lane 1). (B) Type III collagen (lane 2). (C) Biopsy specimen (lane 3).
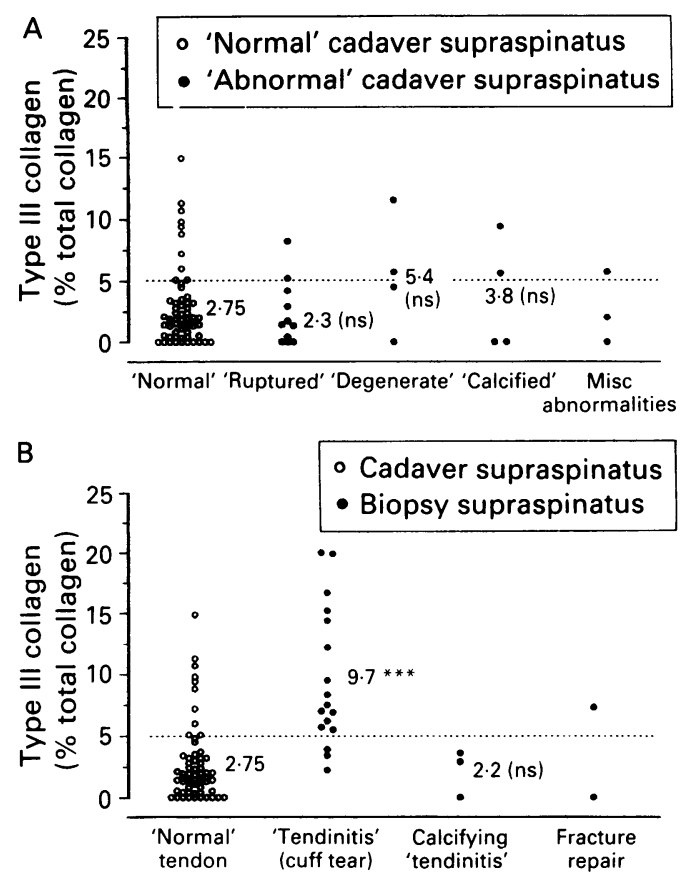

c

TYPE III COLLAGEN CONTENT OF 'NORMAL' CADAVER TENDONS

The type III collagen content was expressed relative to the total collagen content of the tendon, rather than as a proportion of the soluble collagen, because this allowed a better comparison between specimens with different solubility. It is therefore important to note that the data represents the minimum soluble type III collagen content of the tendon.

The majority of the cadaver supraspinatus tendon specimens contained on average less than 3\% soluble type III collagen, although there was a wide range of values (range $0-14 \cdot 9 \%$ ). See fig 5 A.

Ten of the $60(17 \%)$ macroscopically 'normal' specimens contained more than 5\% type III collagen. These specimens tended to have a high collagen solubility (mean $78.3 \%$ ) and ranged in age from 18 to 95 years (mean $57 \cdot 7)$. The hospital and post mortem notes did not record any medical history that distinguished these specimens from the rest of the 'normal' sample, except for a specimen from a 25 year old paraplegic, which might have been expected to have endured unusual stresses and strains. However, a high collagen solubility did not necessarily correlate with an increased concentration of type III collagen. For example, 19 specimens were greater than $60 \%$ soluble and 12 of these had a type III collagen content of less than $4.5 \%$ (mean $2 \cdot 3 \%$ ). In addition, only one of the common biceps tendons had any detectable type III collagen $(<2 \%)$, although six specimens were more than $50 \%$ soluble in cyanogen bromide.

\section{MACROSCOPICALLY ABNORMAL CADAVER}

TENDONS

Although there was no significant difference on average from the 'normal' cadaver sample, seven of the $22(32 \%)$ macroscopically 'abnormal' cadaver specimens contained more than $5 \%$ type III collagen, including two of the

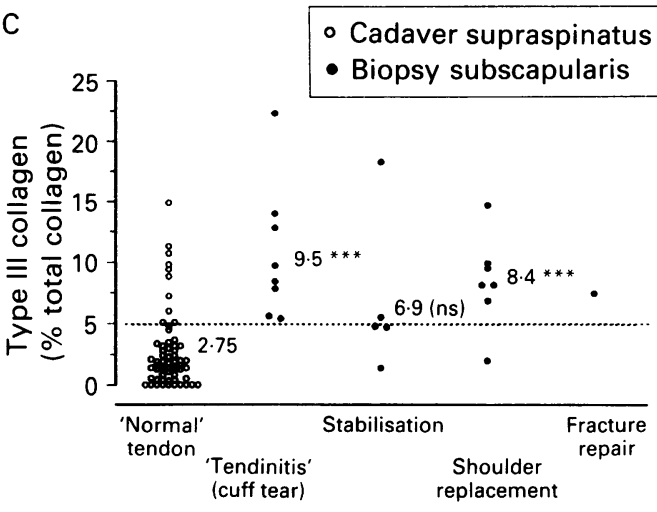

Figure 5 Type III collagen content of rotator cuff tendons. Cyanogen bromide soluble collagen was analysed by $12 \cdot 5 \%$ SDS PAGE and the type III collagen content was estimated by gel-scanning of representative peptides, calculated as a proportion of the total collagen content. Data represent the mean of at least two gel-scans of 60 'normal' cadaver tendons (11-95 years, mean 57.7) compared with: $(A)$ Macroscopically 'abnormal' cadaver tendons comprising 11 'ruptured' tendons (60-94 years, mean $81 \cdot 2)$, four 'degenerate' tendons (67-91 years, mean $81 \cdot 8)$, four 'calcified' tendons (76-94 years, mean 80.2) and three tendons with 'miscellaneous abnormalities' (43-84 years, mean 57.3). (B) Biopsy specimens of supraspinatus tendon, comprising 17 specimens from rotator cuff tendinitis (38-80 years, mean 59.5), three specimens from calcifying tendinitis (47-51 years, mean 49.3) and two specimens from humeral fractures (25 and 78 years respectively). (C) Biopsy specimens of subscapularis tendon, comprising eight specimens from rotator cuff tendinitis (68-80 years, mean 73.4), five specimens from stabilisation operations (19-31 years, mean $25 \cdot 2), 7$ specimens from shoulder replacement operations (40-76 years, mean 57.3) and a single specimen from a humeral fracture (25 years).

$\star \star \star=p<0.001, n s=$ not significant.

11 'ruptured' tendons, two of the four 'thin/ degenerate' specimens and two of the three 'calcified' specimens (fig 5A).

BIOPSY SPECIMENS FROM PATIENTS WITH ROTATOR CUFF TENDINITIS

There was a significantly greater proportion of type III collagen in biopsy specimens from patients with chronic rotator cuff tendinitis. Eighty two per cent $(14 / 17)$ of the supra- 
spinatus tendon specimens contained more than $5 \%$ type III collagen and $100 \%(8 / 8)$ of the subscapularis specimens contained greater than $5 \%$ type III collagen. (fig $5 \mathrm{~B}, \mathrm{C}$ ).

Of the remaining tendon biopsies, only the specimens obtained from shoulder replacement operations had a significantly higher type III collagen content $(p<0.001)$, although two of the three specimens from acute shoulder injuries and two of the five specimens from stabilisation operations contained over 5\% type III. The three specimens from calcifying tendons, although very soluble in cyanogen bromide, had a mean type III content of just $2 \cdot 2 \%$ (range $0-4 \cdot 1 \%$ ).

\section{Discussion}

In this study we have shown that the total collagen content of the normal supraspinatus tendon does not change significantly with age and was similar to the common biceps tendon, a flexor tendon that is rarely involved in any pathology. A higher collagen concentration has been reported in some animal tendons, although the range varies from $50 \%$ to $85 \%$ of the tendon dry weight. ${ }^{31}$ Many of the degenerate tendons from cadavers and biopsies from patients with tendinitis had a decreased collagen concentration and this change may predispose the tendon to rupture, as a reduction in the collagen density has been correlated with the tensile strength of tendons. ${ }^{32}$

In some specimens, a reduction in collagen concentration was found in tendons which were mineralised with calcium salts, perhaps associated with an increase in the tendon dry mass. The exact nature of these crystals is unknown and it remains to be determined if calcium deposits are associated with any of the other specimens with a low collagen content. Calcific deposits have been associated with tendon rupture, although it is not known if these deposits are primary or secondary to the tendon degeneration. ${ }^{33}$

A potentially important physico-chemical property of the ageing human tendons was the extremely insoluble nature of the tendon collagen. This age-related change could be attributed to the maturation of inter-molecular cross-links, although the initial results of a study of a group of young ( $<35$ years) and old ( $>70$ years) cadaver tendons, showed that hydroxypyridinium cross-links remained constant across the age range (unpublished observations in collaboration with Professor Eyre, Department of Orthopaedics and Biochemistry, University of Washington, Seattle, USA). It is speculated that advanced glycation end (AGE's) products, which occur as a result of the accumulation of reducing sugars on long-lived proteins, ${ }^{34}$ are at least partly responsible for this change in solubility. Mature tendon has a high concentration of collagen cross-links and will be less elastic and prone to tendon fibre strains. In addition, the turn-over and remodelling of the tendon collagen may be significantly affected, as mature, cross-linked collagen is resistant to enzyme digestion and relatively inert. ${ }^{35}{ }^{36} \mathrm{An}$ analysis of the different cross-links of the normal and degenerate supraspinatus tendons will provide important information regarding the synthetic activity of the matrix and the turn-over and degree of maturation of the collagen fibres.

Normal tendons are characteristically composed of greater than $95 \%$ type I collagen, arranged in parallel fibre bundles, with relatively small amounts $(<5 \%)$ of the collagen types III, IV and V. ${ }^{21}$ Type III collagen is codistributed with type I collagen in many tissues, but it has previously been shown to be restricted to the endotenon surrounding the fibre bundles in normal tendon. ${ }^{37}$ Consequently, an increase in type III collagen in tendon is generally considered pathological, where it is distributed throughout the tendon matrix. ${ }^{22}$ However, type III collagen can also be found in heterotypic fibres throughout the normal tendon collagen fibres. ${ }^{38}$ The collagen fibre diameter is inversely proportional to the type III content, and type III collagen tends to form thin, reticular fibres in a random meshwork. ${ }^{23}$ Therefore an increased proportion of type III collagen has important consequences for the structural integrity of the tendon and is likely to seriously reduce the ability of the tendon to resist tensional forces, predisposing the tendon to rupture at normal physiological loads.

The biopsy specimens of rotator cuff tendons from patients with tendinitis were from middle aged and elderly patients, which have ruptured following some degenerative process, which is yet uncharacterised. The pathology of tendinitis has been associated with a number of factors, including age related changes in the collagen and mechanical trauma. ${ }^{39}$ These tendons had a reduced collagen density and a greater proportion of soluble type III collagen than 'normal' cadaver tendons. In addition, the water content was increased and the collagen was more soluble in pepsin and after cyanogen bromide treatment. These properties are consistent with new collagen synthesis, such as that seen during wound healing in an attempt to repair a tissue defect. ${ }^{19}$ Clearly some cells in the tendon are capable of an altered pattern of collagen and new matrix synthesis. The origin of these cells is not known and a study of this nature cannot tell us whether this is a secondary response to the tendon rupture or a primary event that may weaken the tendon and predispose to rupture.

Subscapularis tendons were obtained from humeral head fractures, young patients with unstable shoulders ('stabilisation' operations) and from older patients requiring a shoulder prosthesis (shoulder replacements). These tendons could not be considered representative of normal tissues given the likelihood of soft tissue trauma in these shoulders. It is interesting, however, that many of these tendons also contained an increased proportion of soluble type III collagen, although there was no visible evidence of a tendon fibre rupture. It is possible that there were microscopic tears of tendon fibres within the tendon mid-substance and that the increased 
proportion of type III collagen represents an attempt to repair the tendon defect.

A significant proportion of the 'normal' cadaver supraspinatus tendons $(10 / 60)$ also contained an abnormally high concentration of type III collagen. The initial injury in these tendons might result from trauma, possibly of small and repeated tendon strains, resulting in microscopic fibre tears and disruptions in the tendon mid-substance. Many tendon tears are found within the tendon matrix and do not open out to the tendon surface. ${ }^{40}$ Alternatively the change in collagen type might be a response to hypoxia in the tendon, which has frequently been associated with the degeneration that occurs before tendon rupture. ${ }^{12}{ }^{13}$ Recently it has been shown that vibration and repetitive trauma cause a transient increase in the expression of insulin like growth factor (IGF-1) by internal fibroblasts in rat tendons. ${ }^{41}$ IFG-1 stimulates the synthetic activity of fibroblasts, and in tendons exposed to vibration trauma results in an abnormal secretory pattern. The acute and long term effects on tendon matrix synthesis and degradation are not known and may involve additional growth factors, not yet characterised.

In a previous histological study, we showed that degenerative changes are commonly found in many cadaver supraspinatus tendons with no history of shoulder pain. ${ }^{42}$ This study has shown that changes in the collagen concentration, solubility and composition of the supraspinatus tendon accompany tendon degeneration and confirms our belief that biochemical changes in tendon matrix may predispose a proportion of individuals to chronic rotator cuff tendinitis and tendon rupture.

This study was supported by a project grant from the Arthritis and Rheumatism Research Council.

1 Allander E. Prevalence, incidence and remission rates of some common rheumatic diseases and syndromes. Scand fome common $1974 ;: 145-53$.

2 Chard M D, Hazleman B L. Shoulder disorders in the elderly (a hospital study). Ann Rheum Dis 1987; 46: 486-7.

3 Binder A I, Bulgen D Y, Hazleman B L, Roberts S. Frozen shoulder: a long-term prospective study. Ann Rheum Dis 1984; 43: 361-4

4 Bulgen D Y, Binder A I, Hazleman B L, Dutton J, Roberts S. Frozen shoulder: prospective clinical study with an evaluation of three treatment regimens. Ann Rheum Dis 1984; 43: 353-60.

5 Chard M D, Satelle L M, Hazlemann B L. The long term outcome of rotator cuff tendinitis-a review study. $\mathrm{Br} \mathcal{F}$ Rheum 1988; 27 : 385-90.

6 Berry H, Fernandes L, Bloom B, Clarke R J, Hamilton E D B. Clinical study comparing acupuncture, physiotherapy, injection and oral anti-inflammatory therapy in shoulder cuff lesions. Curr Med Res Op 1980; 7: $121-6$.

7 Fearnley M E, Vadasz I. Factors influencing the responses of lesions of the rotator cuff of the shoulder to local steroid injections. Ann Phys Med 1969; 10: 53-63.

8 Chard M D, Gresham A, Hazleman B L. Age related changes in the rotator cuff. $B r \mathcal{F}$ Rheum 1989; 28: 19.

9 Codman E A. The Shoulder. Boston: Todd Co, 1934. Neer C S. Impingement lesions. Clin Orthop 1983; 173: $70-77$.

11 Ozaki J, Fujimoto S, Nakagawa Y, Masuhar K, Tamai S. Tears of the rotator cuff of the shoulder associated with
pathological changes in the acromion. A study in pathological changes in the acromion. A stud
12 Rothman R H, Parke W W. The vascular anatomy of the rotator cuff. Clin Orthop Rel Res 1965; 41: 176-186.

13 MacNab I. Rotator cuff tendinitis. Ann Royal Coll Surg Eng 1973; 52: 271-87.

14 Bielle A. Epidemiology of shoulder problems. In: Hazleman B L, Dieppe P A, eds. The shoulder joint. London: Balliere Tindall, 1989, 437-51.

15 Van de Rest M, Garrone R. Collagen family of proteins. FASEB ₹ 1991; 5: 2814-23.

16 Burgeson R E, Nimni M E. Collagen types: Molecular structure and tissue distribution. Clin Orthop 1992; 282:250-72.

17 Mays P K, Bishop J E, Laurent G J. Age-related changes in the proportion of types I and III collagen. Mech Ageing Dev. 1988; 45: 203-12.

18 Adam M, Deyl Z. Degenerated annulus fibrosus of the intervertebral disc contains collagen type III. Ann Rheum Dis 1984; 43: 258-63.

19 Bailey A J, Bazin S, Sims T J, LeLous M, Nicoletis C, Delaunay A. Characterisation of the collagen of human hypertrophic and normal scars. Bioch Biophys Acta 1975; 405: 412-21.

20 Bazin S, Le Lous M, Duance V C, et al. Biochemistry and histology of the connective tissue of Dupuytren's disease. Eur 7 Clin Invest. 1980; 10: 9-16.

21 Von der Mark K. Localization of collagen types in tissues. Int Rev Connect Tissue Res 1981; 9: 265-324.

22 Williams I F, McCullagh K G, Silver I A. The distribution of types I and III collagen and fibronectin in the healing equine tendon. Conn Tiss Res 1984; 12: 211-22.

23 Lapiere Ch.M, Nusgens B, Pierard G E. Interaction between collagen type I and type III in conditioning bundles organization. Conn Tiss Res 1977; 5: 21-9.

24 Bergman I, Loxley R. Two improved and simplified methods for the spectrophotometric determination of hydroxyproline. Anal Biochem 1963; 35: 1961-5.

25 Laemmli U K, Favre M. Maturation of the head of bacteriophage T4. ₹ Mol Biol 1973; 80: 575-99.

26 Sykes B, Puddle B, Francis M, Smith R. The estimation of two collagens from human dermis by interrupted gel electrophoresis. B B Res Comm 1976; 72: 1472-80.

27 Towbin H, Staehelm T, Gordon J. Electrophoretic transfer of proteins from polyacrylamide gels to nitrocellulose sheets. Proc Natl Acad Sci USA 1979; 76:4350-4.

28 Miller E J, Kent Rhodes R. Preparation and characterization of the different types of collagen. Meth Enz 1982; 82: 33-64.

29 Laurent G J, Cockerill P, McAnulty R J, Hastings J R B. A simplified method for quantitation of the relative amounts of type I and type III in small tissue samples. amounts of type I and type III in

30 Hanson A N, Bentley J P. Quantitation of type I to type III ratios in small samples of human tendon, blood vessels and atherosclerotic plaque. Anal Biochem 1983; 130 $32-40$

31 Elliott $\mathrm{D}$ H. Structure and function of mammalian tendon Biol Rev 1965; 40: 392-421.

32 Haut R C, Lancaster R L, DeCamp C E. Mechanical properties of the canine patellar tendon: some correlations with age and the content of collagen. 7 Biomechanics 1992 ; 25: $163-73$.

33 Kannus P, Jozsa L. Histopathological changes preceding spontaneous rupture of a tendon. $\mathcal{F}$ Bone foint Surg. 1991; 73A: $1507-25$.

34 Sell D R, Monnier V M. Isolation, purification, and partial characterization of novel fluorophores from aging human insoluble collagen-rich tissue. Conn Tiss Res 1989; 19: $77-92$.

35 Laurent G J. Dynamic state of collagen: pathways of collagen degradation in vivo and their possible role in regulation of collagen mass. Am $\mathcal{f}$ Physiol 1987; 252: C1-C9.

36 Robins S P. Turnover and cross-linking of collagen. In: Weiss J B, Jayson M I V, eds. Collagen in health and disease. London: Churchill Livingstone, 1982, 160-78.

37 Duance V C, Restall D J, Beard H, Bourne F J, Bailey A $\mathrm{J}$. The location of three collagen types in skeletal muscle. FEBS Lett 1977; 79: 248-52.

38 Keene D R, Saki L Y, Bachinger H P, Burgeson R E. Type III collagen can be present on banded collagen fibrils regardless of fibril diameter. F Cell Biol 1987; 105: 2393-402.

39 Cofield R H. Current concepts review: rotator cuff disease of the shoulder. F Bone foint Surg 1985; 67A: 974-9.

40 Yamanaka K, Fukuda H. Ageing process of the supraspinatus tendon with reference to rotator cuff tears. In: spinatus tendon with reference to rotator cuff tears. In: Watson M S, ed. Surgical disorders of the shou

41 Hansson $A$ A Dublin L B, Lundborg G, Lowenadler B Paleus S, Skottner A. Transiently increased insulinlike growth factor immunoreactivity in tendons afte vibration trauma. Scand $\mathcal{f}$ Plast Reconstr Surg. 1988; 22 $1-6$

42 Chard M D, Cawston T E, Riley G P, Gresham G A, Hazleman B L. Rotator cuff degeneration and lateral epicondylitis-a comparative histological study. Ann Rheum Dis 1994; 53: 30-34. 